\title{
Body? What Body? Considering Ability and Disability in STEM Disciplines
}

\section{Prof. Amy E. Slaton, Drexel University}

Amy E. Slaton is a professor of history at Drexel University. Her most recent book is Race, Rigor and Selectivity in US Engineering: The History of an Occupational Color Line. She is currently writing on issues of equity surrounding high-tech workforce preparation. 


\title{
Body? What Body? Considering Physical Ability and Disability In STEM Disciplines
}

\begin{abstract}
Issues of minority inclusion in STEM fields, marking the presence or absence of certain groups in these disciplines, are often treated by analysts as "inside/outside" problems: some groups are included, some are not, we learn, and the resulting discrimination needs to be addressed by securing inclusion for the "missing" folk. That dichotomous understanding, however, hides the complicated marginalities within marginalities inhering in American science and technology sectors. The educators and policy makers who have worked to correct STEM underrepresentation are themselves often treated as outside the pedagogical mainstream; the rare historian or sociologist concerned with matters of identity and equity in science and technology is less explicable still to his or her home discipline. And as little explored as race, gender, and LGBT identity might be, physical ability and disability in STEM disciplines remain subjects with even less presence in social scientific spheres. This paper considers this absence: why $d o$ persons with disabilities constitute an identity that remains underexplored in STEM education theory, marginalized in institutional planning, and nearly invisible in critical social scientific studies of those fields, even where other forms of exclusion have come under study? What ideas about bodies and intellectual abilities and the linkages between them are foundational to STEM, and why have social scientists almost completely failed to consider these powerful cultural normativities? By extension, what might the methods of Science and Technology (or Engineering) Studies bring to such study? Do receptive audiences for such an inquiry exist? Using the case of a visually impaired undergraduate at a large state university who explicitly addressed the discriminatory epistemological suppositions of her lab course instructors, this paper will describe presumptions made about the student's abilities; about the nature of learning in STEM fields; and about precision and accuracy in scientific data as functions of some bodies and not others. Preparatory to a larger study of students with disabilities in laboratory settings, this paper asks, as well, if risks - either analytical or reputational-- accrue to those personsdisabled or non-disabled--who undertake such analyses.
\end{abstract}

Introduction

This is a brief discussion of ideas of competence, opportunity, and bodily normalcy in the places where engineering is performed. In American classrooms, laboratories, factories, and construction sites; at engineering industry trade shows and academic meetings; in the halls of funding agencies and engineering-firm HR departments, ideas about intellectual and physical disability are in constant circulation. These ideas are virtually never openly discussed as such, yet routine judgments about eligibility for participation in any of these spheres devolve onto notions of who is able and who is not. The very occasional presence in these settings of persons with visible disabilities both elicits a telling surprise among the non-disabled, and makes explicit a set of discriminatory notions operating to exclude many other individuals with such "deficiencies," and also with other less visible impairments, from engineering occupations. How can we understand the origins and impacts of these notions? 
This paper does not survey the extensive literature on STEM teaching and learning for persons with disabilities, but instead suggests a set of social scientific questions about STEM education that may help us determine why the participation of these persons remains low. I focus here on engineering education as a site in which the values and aims of engineering are articulated and reproduced. Post-secondary engineering programs take as their objective professional preparation, of which socialization is a central feature. Thus, it is the university that instills many basic ideas about occupational opportunity, bias, and fairness in those who ultimately gain admission into the engineering occupations. Central to this paper is the belief that such socialization and the parallel intellectual preparation of future engineers (i.e., the teaching of socalled technical skills) are mutually constitutive activities. I want to suggest how constructions of rigorous technical thought and practice embody discriminatory social structures around disability.

The particular practices I am concerned with are perhaps those least likely to be construed as having a social aspect: measurement, data collection, and other instrument-based tasks of engineers. Using frameworks established in Science and Technology Studies and the History of Science, I understand these tasks to constitute the labor of producing and representing knowledge about materials but also to express the political and social relations from which engineering (one social collectivity functioning amidst others) derives. ${ }^{1-3}$ Among those relations are those that discourage STEM involvement by persons with disabilities by means of epistemological arguments: for example, by denying that a visual representation of data might be efficaciously replaced by an audio or tactile one; or that hands-on and observational exercises might be equivalent to one another; or that different persons might justifiably use different instruments to undertake the same technical learning or labor. In short, this paper sketches a politics of engineering epistemologies around issues of disability.

This is part of a larger project regarding the meanings of identity in STEM education more generally, a body of work by scholars loosely grouped under the emergent Engineering Studies (ES) rubric. ${ }^{*}$ This scholarship is not extensive but in the last few years it has carefully considered the social instrumentality of categories including race, class, gender, LGBT identities, and age as enacted in engineering. ${ }^{4-7}$ Such critical studies stand at some distance from most policy work on STEM diversity, which largely seeks to encourage the participation of underrepresented groups in existing institutions along the lines of existing standards of practice. That work unquestionably produces important ameliorations of student experiences, but does not undertake profound cultural critique that might point to underlying sources of STEM inequity.

By contrast, critical ES scholars look at the ways in which categories of identity or difference, and such performance standards about what is good or valuable engineering practice, jointly gain meaning in places of STEM teaching and learning. ${ }^{8-10}$ That is, the aim of this kind of study is to identify oppressive or exclusionary conditions within engineering, but also to ask if the entry of

*The term "Engineering Studies" is sometimes used to refer a sub-field of "Science and Technology Studies," and self-identified Engineering Studies scholars make use of methods associated with "Science Studies." No clear lines can be drawn between any of those fields and the fields of History and Sociology of Science and Technology. All of these rubrics are in a state of flux and I use Engineering Studies here for convenience. 
underrepresented groups into existing institutions and practices necessarily constitutes an emancipatory gesture. If engineering as a profession reflects social and cultural privilege (as the field is currently populated in university, corporate and state settings), ES asks, how can the expertise that constitutes engineering, and the field's resulting projects, not also embody social oppressions? A crucial point with which to begin this conversation involves old cultural presumptions that physical disability is necessarily associated with intellectual impairment; visible and audible bodily differences are still readily assumed in U.S. culture to be accompanied by cognitive limitations. That is by all means a discriminatory presumption that should be vigorously negated. However, it is very important to understand that we must also question our definition of intellectual wholeness. In those ideals, too, we will find exclusionary presumptions and these are the objects of my analysis here.

It is not only engineering students and prospective professionals who are shaped by discriminatory meanings and ascriptions, of course, because in the United States many persons of color, low socioeconomic standing, and non-heterosexual self-identity detect no opening even to imagine themselves as engineers and never undertake training. That overriding cultural construction of engineering as white, male, and heteronormative drives inquiry about identity for many Engineering Studies scholars and I want to propose ideas for approaching the ableist biases of engineering in the same terms. While research in teaching-and-learning fields has considered specific K-16 STEM interventions for persons with physical or intellectual disabilities in a variety of disciplinary settings, like educational policy research this is not work that theorizes STEM knowledge-making as a social or cultural enterprise ${ }^{11}$ Although sometimes extraordinarily creative in recognizing the arbitrary nature of discursive customs in STEM instruction and in instituting inclusive alternatives ${ }^{12}$, it does not take as its purview critique of the academy as a social structure or political analysis in any other sense. Conversely, the field of Disability Studies, deriving from recent social theory and cultural criticism, seems to hold great potential to deepen inquiry on STEM as a social realm writ large: As Siebers has written, "Disability identity stands in uneasy relationship to the ideology of ability, presenting a critical framework that disturbs and critiques it"'(p.9). ${ }^{13}$

As is the case with any study of oppressive cultural patterns, even a preliminary outline of the issues here poses dauntingly complex challenges of demarcation and self-reflection. In recent decades, disabilities scholars have made central to their work questions about self-identification among communities of disabled persons and questions about experiences of differences. That field often engages with minority studies more generally to ask about social science as a political project, and the recursive challenges involved are many. This literature, with notable reflexivity, routinely asks of itself, "Who speaks here, and from what vantage point, about disability?"14-16 I do not presume to digest this literature here. But I do aim to suggest that inclusion can be approached in more and less trivial ways and to encourage the latter by asking how engineering education defines "disability" and why; what counts as participation and proficiency; how engineering teaching and learning as currently constituted can and cannot admit of assistive technologies and other classroom accommodations; what might constitute emancipatory change to any of these conditions; and why I (as a non-disabled person and non-engineer) am or am not in a position productively to ask these questions. 
My narrow objective is to see how engineering functions as an ableist enterprise on the basis of essentialist notions of intellect, drive, and self-discipline that center on bodily "normalcy." I see this project as continuing a wider exploration (begun in my work on the whiteness of American engineering ${ }^{7}$ ) of how best to understand the role of technical content (epistemologies) in forwarding social privilege, under somewhat urgent political conditions. Contemporary rhetoric around the benefits of STEM diversity is shot through with the idea that right-thinking Americans can apply their innate intellectual abilities in STEM fields reliably to attain both individual economic security and contribute to national well-being. ${ }^{17-18}$ But this promissory language disguises a stratified economic and social system, pervaded with inequities. ${ }^{19-21}$ This paper is an attempt to integrate the theoretical tools and activist concerns of Disability or Minority Studies and those of Engineering Studies to shed light on this troubling neoliberal climate. The former--scholarship on identity and equity--suggests means of understanding the constructed nature of human differences; Disability Studies (henceforth, DS) has also addressed issues of intersectionality and authorial voice with notable rigor. ${ }^{5,16,22}$ The latter - the socially inflected study of engineering (along with the history of science and the sociology of scientific knowledge)--brings precision to our analysis of intellectual competence in industrial cultures, as a matter of historically changing and subjective ascription. ES provides a model of bench-level ethnography and material investigation that empowers deep critique of opportunity structures in science.

The activities surrounding measurement, record-keeping and instrument use of all kinds in STEM fields offer a telling but underused lens on the function of social and political ideologies in scientific labor. No scientific inscription is unmediated by ideas of belonging, of who may reliably inscribe. All instrument use is inherently social. ${ }^{1-3,23-25}$ As Saunders summarized in his ethnography of the CT scanning clinic, scientific instruments introduce, “...new forms of discontinuity and exchange within systems of expert labor, viewing practices, rhetorics of testimony, training regimes, modes of experience" (p. 12). ${ }^{26}$ A combined DS/ES approach shows that each of those "new forms" and many others can be found in places of STEM education in ways that enact discrimination against socially marginalized groups. Here, I will first describe the socially constructed nature of disabilities and then sketch the particular ways in which STEM metrology asserts ideas of bodily and cognitive difference. Next, using the case of a visually impaired undergraduate at a large state university who explicitly addressed the discriminatory epistemological suppositions of her lab course instructors, this paper will outline presumptions made by instructors about the student's abilities; about the nature of learning in STEM fields; and about precision and accuracy in scientific data as functions of some bodies and not others. This paper lays out a set of analytical categories with which we might approach pedagogical practices around STEM and disability and asks, as well, if risks-either analytical or reputational-- accrue to those who undertake such analyses.

\section{The Social Construction of Disability}

The means by which physical and intellectual disability may lead to a student's exclusion from STEM curricula and potentially corrective measures to achieve inclusion are articulated routinely in educational and policy circles. Disability services have existed in U.S. universities for decades, providing varying levels of support and accommodation for students with sensory impairments, limitations to mobility or dexterity, chronic illnesses, and/or intellectual or learning 
differences. The Individuals with Disabilities Education Act of 1975 and the Americans with Disabilities Act of 1990 brought new resources and systemization to these services. Those legal and institutional developments are seen by many to be a delayed but authentic extension of de jure and de facto civil rights developments of the 1960s, as would seem to be confirmed by the fact that the National Science Foundation has funded dozens of studies over the last twenty years on disability-focused teaching and learning in STEM contexts, covering many academic disciplines and a range of disabilities. ${ }^{11}$

However, the development and assessment of inclusive STEM pedagogies, including the use of assistive technologies, is not having as wide an impact as might be desired. Commitments to the principals of Universal Design for Learning (UDL), which aim to prevent marginalization by designing universally accessible materials and worksites in the first place, remain rare in university science and engineering programs despite their proven benefits for learners of all kinds. Limited institutional resources for inclusive efforts of that kind and negative attitudes towards persons with disabilities intersect to help keep the representation of those with disabilities in the nation's STEM workforce far below their representation in the population overall ( 2 percent versus 10 percent). ${ }^{11}$ As Orr and Hemmig summarize, common accommodations (in this instance, for students with learning disabilities) such as extended time on tests, modified assignments, and technologies which include screen readers or books on tape, may routinely be offered through formalized protocols in a school, yet:

...prescribed accommodations only serve students who identify themselves as having a disability, and seek support. Such retroactive adjustments generally do not address barriers embedded within the curriculum design, and may or may not increase faculty understanding of best practices for [students with disabilities] (p. 182). ${ }^{27}$

As is the case in other instances of identity-based discrimination in America, even the most energetic and best intentioned practitioners continue to operate in settings that tolerate limited reform.

Critical social scientific work on disabilities has offered important framing for understanding this ongoing inequity. To my mind, foremost among its contributions is the idea, developed during the 1990s, that that which a culture treats as physical or mental capacity derives from social values and conditions. This "social model" of disability to a degree displaced a "medical model" that had sought to identify and treat individuals' bodily or intellectual deficits as unproblematically defined objects. Humphrey describes the sociologists' concern with, "the nature of a disabling society in terms of the physical environment, the political economy, the welfare state and sedimented stereotypes," as well as with "the experiences of disabled people" (pp. 64-65). ${ }^{16}$ The social model suffers from its own risks of essentialism, Humphrey notes (p. 69), but does empower a constructivist critique. For its part, the medical model assuredly has some potential to interrogate power relations (say, how medical expertise disavows patient experience or how the pharmaceutical industry reproduces marginalizations and stigmas). But it also often encourages a dichotomous model of health and illness, ability and disability, one which in turn can only be deeply problematized by socially contextualizing, constructivist analysis. $^{28}$ 
Theorists of the constructivist bent propose that disabilities, like any other feature of our selves or others that we would recognize as a bodily or cognitive characteristic, are not "things out there," not natural categories awaiting diagnosis and remediation. ${ }^{29}$ Rather, that which is defined by a culture, institution or discipline as a disability indicates a perceived absence, a failure to match some expectation or demand. Building on Foucauldian understandings of the ways in which expert knowledge derives from and expresses social power, these analyses demonstrate that definitions of optimized practice (in a community, home, hospital, workplace or classroom) delineate optimized persons (in terms of bodies, behaviors, cognitive habits, etc). ${ }^{30}$ The relationship between disability and social context is not one of figure and ground; rather agentic individuals, practices, and social structures all play dynamic parts in this process of declaring that, "here is difference." Simply raising the question, "Who is saying that this is a meaningful difference?" highlights that dynamism and complexity.

We should consider the distance between that way of thinking about a STEM student's experience and one which uncritically maps the address of a student's hearing impairment or mobility limitation by way of the boilerplate description in a Disabilities Services handbook. The processes by which beliefs about difference become instantiated in societal practices are much debated among social theorists, ${ }^{15,28,29}$ and those debates cannot be addressed in this short essay. But the understanding that definitions of physical and intellectual capacities are necessarily subjective indicates that the labels and categorizations deployed in STEM education ("abled" and "disabled," "strong student" or "weak") are historically contingent. Accumulating expertise regarding best practices (that is, formal pedagogies of disability) can itself foreclose understanding of that contingency. In discussing the use of IQ to identify persons of low intellectual capacity, Rapley gives a good sense of how the invention of diagnostic labels and their deployment can bring about such foreclosure:

...less careful descriptions of the "condition" may actively confect an historic continuity of the proposed identity between IQ test scores and the category of personhood ascribed on their basis (p. 34). ${ }^{29}$

The existence of a ranking posits subjects of high and low ability as if those were not judgments always already dependent on what is being asked of the subjects. For these reasons, the existence of disabilities services and empirical expertise about disability within the academy should not by itself be equated with liberatory change in any simple way, any more than should the legal protections wrought by the ADA or specific adaptive technologies, however innovative.

\section{The Social Construction of STEM Ability}

No STEM textbook, research paper or lab manual that I know of guides its users to think about their own bodies as they read, in either an immediate or analytical sense. It does not matter, ostensibly, if one is hot or cold, energized or tired, comfortable or in pain while ingesting chemistry or physics knowledge. Nor is one's gender, race or age an appropriate topic for address in the pursuit of a STEM education except in strongly delineated "diversity" programming (see below). Authors' bodies are not to be mentioned either; no selves at all, in fact are welcome: using "I" or "we" in scientific writing is a mark of occupational naiveté. ${ }^{31}$ STEM elides bodily experience. Genetics texts may urge students to consider their own and their 
parents' eye colors, nursing students may be told to take their own pulses, and lessons in lab or field safety (to which I'll return) draw very particular kinds of attention to practitioners' bodies, but these are exceptions that prove the rule. By contrast, texts in disabilities, gender or race studies; cultural anthropology; and literary criticism have moved towards foregrounding corporeality and reveal just how committed STEM fields are to the appearance of being locations where, in Siebers words, "bodies do not seem to matter who we are" (p.7). ${ }^{13}$

Helpfully, historians of science and technology have already done a great deal to show that despite that rhetorical elision, ideas of normal and deviant, or abled and disabled bodies, are replete in STEM enterprises and always have been. Eligibility for scientific credibility always resides in bodies. The reliable eye and well controlled hand (encapsulated in the ideas of the "personal equation") have mattered deeply in Western science from at least the $18^{\text {th }}$ century, as scholars working on the role of objectivity and instrumentation in science and (in far fewer numbers) engineering have shown. ${ }^{2,23-25,32}$ The at-risk or injured researcher's body, under selected conditions, has long indicated a certain kind and level of scientific engagement. ${ }^{33}$ Most obviously, racialized ideas of intelligence, including some based in genomic science, assert the belief ongoing in industrial cultures that subjects' bodies are determinative of their cognitive capacity. ${ }^{7,34,35}$ In American engineering, the connection of non-black, -Hispanic or -Native American race and male gender with technical competence, as well as the enduring hetereonormativity of the field, make it clear that bodies do matter, deeply, in STEM as everywhere else. $5,7,36,37$

The central historical lesson about the denial of bodies in STEM discourse is this: Rhetorical silence about bodies is in fact a choice and a means of avoiding constructive address of difference, of inequity. Siebers makes clear that a broader backing away from minority identity as potentially constructive social force in recent decades has accompanied the emergence of neoliberal ideals of "disinterested and unique selves" (p. 94). ${ }^{13}$ In the United States we live in a world in which difference is constituted as having value in an extremely selective way. We operate with a kind of "corporate diversity" which values cultural divergences of only very limited kinds (say, celebrating diverse ethnic heritages in a workplace or classroom, but eliding the class differentials or political differences that may historically accompany those heritages). ${ }^{38}$ Differences which derive from power relations, and whose recognition would highlight those relations, are omitted from the rubrics. It is not hard to see how authentic address of physical or intellectual disability might be limited in this kind of cultural atmosphere.

But it is important to recognize that the epistemological conventions of STEM enact this limitation in particular ways. To begin with, reputable post-secondary STEM programs are above all striving to be sites of standardized reasoning and behavior: As in all modern scientific settings what counts as accuracy and completeness is not seen to be a matter of discretion for those who wish to succeed. ${ }^{25,31}$ That may sound like a truism but it is a helpful formulation for thinking about STEM inclusion. Programs and the students they serve regulate both what is learned, and how; the student who requires six years to complete an engineering degree is widely understood to be less accomplished and less promising than the one who requires only four or five (such flexibility of opportunity is of course very rarely provided ${ }^{7}$ ). What counts as good, rigorous work is felt to be measurable against a knowable and known ideal, as these things may 
be expressed on the parts of individual students through performances on exercises and tests, for example.

In engineering, safety, and reliability are commonly offered as unassailable reasons for this pedagogical regulation. Tests, grades, and later in life, licensing exams for technical fields may assure that bridges stand up and artificial hearts perform reliably but they do so in ways that circumscribe which communicative conventions, what pace of learning, and which means of organizing one's knowledge about a bridge or heart valve are of value. Whiggish notions of ever-improving STEM knowledge and practice further hinder reform; complicated software packages that simulate, say, dissection or statics cases, serve visually or physically impaired students far less well than do older tactile models. ${ }^{11}$ The veneration of epistemic novelty is an old issue in engineering education, having characterized so-called shop/school and theory/practice debates for the last 200 years (with, ironically, all sides claiming new understandings of cognitive processes involved in engineering). ${ }^{2}$ But all such discourse reflects the ways that those with cultural authority valuate technical practices and practitioners. These have become utterly inseparable judgments, as I see it, and ones which come to dominate cultural understandings of knowledge. That inseparability and its consequences for STEM inclusion are dramatically illustrated in a meticulous study of a self-taught automobile mechanic by anthropologist Douglas Harper. Harper records the welder's successful reliance on the sights, smells, and sounds of tool and metal, rather than on established bodies of scientific findings or customary shop practices, to create a complex body of metallurgical knowledge. Harper urges us to acknowledge our own surprise at the mechanic's rigorous and efficacious technical practice. ${ }^{39}$

Behind the adherence to any specific performance standards resides the idea that such standards are a reliable means of assuring merit-based, fair life opportunities. ${ }^{19,21,40}$ Since educational methods in America are widely presumed to arise from democratic ideologies and the notion of discriminatory standards is nearly unimaginable, to express doubt about the value of standards is to challenge the necessity of rigorous technical practice. It is not hard to understand, therefore, why some STEM instructors resist the idea of accommodating differently abled students (or for that matter, students with diverse levels of preparation or acuity) in a classroom or lab. To do so is contrary to the notion of engineering or chemistry proficiency as a body of accumulated facts and skills that have been expertly pre-determined, and to which ad hoc or improvisational changes pose risks. ${ }^{25,31}$ Instruments are particularly important in narrowing down what counts as legitimate engineering activity, severely delimiting observational or measurement practices. That which is worth knowing is recorded by the instrument, in a way that gives the object under scrutiny its meaning; that which the instrument does not record is not worth knowing.

I am very interested in the prospect that assistive technologies may help us expose that narrowness. In lab course accommodations for students with disabilities, text-to-voice or tactile "conversions" (a loaded word in itself, obviously), can be seen as "working just as well" as the familiar metrological modes. Disabilities scholars see epistemic flexibility of this kind as central to effective instruction (say, allowing students to choose a visual or audio means of recording data, or to use multiple inscription devices). As Orr and Hemmig explain, UDL is in fact predicated on an absence of "rigid mandates for particular instructional methods" (p. 192). ${ }^{27}$ But such mandates, and the virtual impossibility of students trying a variety of instructional methods even where those are available, are entrenched in the extraordinarily narrow range of 
instructional options found in the jam-packed syllabi of the jam-packed curriculum comprising the typical undergraduate engineering degree program.

\section{A Suggestive Case}

A brief overview of one case highlights tacit expectations among STEM instructors that might be impeding inclusion and raises questions about conventional standards and resistance to reform. This overview begins the process of shaping a more extensive and comparative study of experiences of disabled students in post-secondary science and engineering lab courses planned to include private and public institutions and to reflect the reported experiences of students, instructors, and diversity/disabilities staff members. (The following account is based on interviews and news coverage, but to protect the anonymity of interviewees I do not cite media sources directly.)

A blind undergraduate student taking chemistry courses in a large state university over the last two years found that instructors were reluctant to have her participate in laboratory exercises without the presence of an aid or partner. In that type of educational accommodation, a school may provide a student with disabilities with an aid who is not taking the class (a staff person or student) or with a classroom partner tasked with reporting procedures and findings to the disabled student as experiments are conducted. ${ }^{11}$ According to a Disabilities Services staff person working with this student, faculty gave several reasons given for the necessity of having an aid in this case. These included the impossibility of the blind student autonomously undertaking the work in a way that would have instructional value, thus invalidating the use of non-visual methods of collecting and recording data; the unmanageable cost of providing assistive technology of that kind; issues of safety; and issues of fairness. How should we see these hesitations?

First, we can consider one professor's feeling that alternative formats for instrument-based work in the lab were simply not pedagogically "viable," in some epistemic sense. What exactly the problem for the blind student might be here, on the level of information conveyed and absorbed, was not articulated by the professor. The blind student worked with the university's Disabilities Services office to investigate assistive technologies and means of procuring and paying for those. One chemistry instructor was particularly responsive to her efforts, as well. Together they located a manufacturer of lab equipment based on text-to-voice technology and for $\$ 900$ obtained a probe that allowed the student to perform laboratory tests. For a professor to object in a meaningful way to the gathering or recording of data by means of this alternative apparatus, he or she would have to articulate some distinction between written and audible inscription. As an epistemological tourist, I would of course like to ask this professor: What would that distinction be?

But such questions are not easily asked. For one thing, under what conditions is it reasonable to ask a professor such a question? Who, after all, can know as well as the instructor what legitimate teaching or learning in a given moment might be? I would not be comfortable having someone question my own pedagogy, certainly, least of all from the vantage point of what counts as meaningful knowledge to be imparted to students. Professorial work is by definition esoteric and in some ways very private (we might think about the challenges we sometimes face carrying 
out our ASEE work in our home departments). Also, in daily practice the nature of technical rigor and precision is not seen to be socially determined but rather driven by inviolable if evolving (along narrow criteria) determinations of best practice. Faculty may feel that they do not know how to teach with assistive technologies, ${ }^{27}$ but I would suggest that the sense of "not knowing" is itself predicated on the a priori idea that unfamiliar inscription formats are just that: essentially unlike those conventionally used in instruction.

The issue of cost is an extraordinarily telling matter in all educational interventions. Of course individual instructors and departments may feel as if they cannot adjust budgets, and institutions do deny resources for all kinds of projects; cost is true problem. But it is one that arises from value systems, not naturally occurring conditions. To use it as the end point of an inquiry about inclusion is misleading. I refer readers here to previous work on racial issues in STEM diversity, explaining how the allocation of funds evades critical address. ${ }^{7}$

Finally, let us consider that the claim heard in this instance that the presence of a blind or otherwise disabled student poses issues of safety in the lab, to the student herself and others sharing the space. In a trivial sense this is of course true, as bodies (being real and vulnerable things!) are subject to risk and injury. But it takes little further thought to realize that the design of the laboratory could be different; the blind student and her receptive instructor in fact purchased cheap textured floor mats to guide the student around the workspace. Again, a set of standard practices which appears to be inevitable actually reflects choices (and principles of UDL would probably question the defensibility of the lab's original safety standards). The notion that a given teaching space is unsafe for persons of sensory impairment or limited mobility should begin, not end, conversations about inclusion.

The idea that that a visually impaired student could not be safe in the chemistry laboratory sheds a raking light on the moral economy of STEM instruction. "Accommodation" and changes of any kind deriving from the needs or positions of students (rather than from inside the customary expertise of STEM professors) challenge ideas central to the culture of STEM. These are not simply hierarchical habits that on principle devalue the experiences of students in favor of expert knowledge. Beliefs about practitioners' character, fortitude, and self-reliance are also at work. Historically, engineering education has ascribed importance to the use of instruments in ways that entwine students' empirical observations with the development of personal traits ranging from self-discipline to honesty to heterosexuality. ${ }^{2,7}$ Intersectionality is no small matter; the student described here is female, a category which can on its own bring with it assumptions of physical and intellectual deficiencies in STEM disciplines. ${ }^{4,6}$ But matters of personality and character and bodies are not made explicit in day-to-day laboratory instruction, only in some other places where engineering education and its aims are foregrounded (like this conference). While it would thus be very difficult to articulate the nature of ideas about self-reliance and the roles those expectations play in STEM faculty resistance to accommodation, it is nonetheless important to explore these.

Questioning the Goals

This focus on moral economy and character leads to an important set of critical questions about the institutions and conceptual frameworks currently available to those who seek greater equity 
in STEM education. Two points in particular seem fruitful. First, I think it is crucial to question the value of self-efficacy as a tool of inclusion. In much of the literature about STEM students with disabilities other under-represented groups, there is an emphasis on empowering students through a building up of self-confidence or self-esteem. As Dunn puts it:

Many of the skills associated with self-determination, such as acknowledging, understanding, and accepting one's disability; knowing one's strengths, weaknesses, and needs; and self-advocating to ensure proper accommodations are provided, have been linked to students with disabilities' persistence and success in STEM (p. 50). ${ }^{41}$

This language is very similar to that used in discussions of other minority groups in STEM. In no sense is self-advocacy a negative thing; it is precisely that aim which might make us wish to rehabilitate the role identity politics in any of our classrooms. But conceptualized as a means of pursuing equitable education or employment opportunities, self-efficacy can turn attention away from structural impediments to inclusion. ${ }^{42}$

The very terms in which a student might think about his or her experience are narrowed, as well. In the case of physical or intellectual disability, what counts as knowledge about oneself seems to involve recapitulating the categories currently on offer: that which status quo lays out as a strength or weakness. Some analysts suggest reframing teaching and learning as matters of "functional abilities" (emphasis added) rather than as occurring within a typology of disabilities. This interesting shift in pedagogical philosophy would seem to encourage a move away from monolithic, expert-derived definitions of student experience (with or without disabilities), towards much more mutable, context-aware, understanding of STEM education. ${ }^{11}$ But even this sort of reframing may devolve uncritically onto existing ideas of what is required for a rigorous classroom experience: How exactly do we open up our ideas of what "functional" might mean?

What is more, where self-reliance (as part of the disciplinary culture) or self-efficacy (as something encouraged among under-represented minorities in STEM classrooms) are valued, some students may be understandably reluctant to self-identify as differently abled. ${ }^{27}$ All of our discourse and research around STEM should include questions about who in our thinking is being cast as holding responsibility for inclusive or exclusive educational experiences. For example, one intriguing study found that the learning disparities between deaf and hard of hearing students under examination arose not from differing student capacities but from differentials in teacher training. ${ }^{11}$ Obviously, in order for a research study to find instructor capacity to be the problem, researchers have to start by considering it to be a factor. Selfefficacy-centered models and measurements of student attainment could bring in this factor but do not routinely do so. ${ }^{42}$

While in some instances like that described above a student has initiated institutional reform, and in others students have led technical projects to create custom-designed assistive apparatus, for many students this is not a physical, psychological or practical possibility. Where self-efficacy is unproblematically celebrated, the absence of such initiative is too easily cast as a shortcoming. That kind of judgment finds support not only in the historically masculinist discourse of engineering, ${ }^{4,37}$ but also in emergent neoliberal models of the efficacious modern citizen. This is an infinitely "flexible and autonomous" learner, ready to work as and where required in a 
global labor marketplace, and to forego security and the accrual of skill in favor of "lifelong learning." ${ }^{19,20,40}$ If the model American is now a self-propelled learner and worker, as a great deal of literature on technical education currently holds, the individual who raises issues of structural inequity is deeply problematic. ${ }^{21,43,44}$ Certainly any notion of shared responsibility for one another as productive citizens, which must underlie truly inclusive reform, is going to be seen as questionable. One longer term goal of this study is to help situate disabilities in the neoliberal context in which all STEM labor is now planned, in order to raise questions about the ways in which labor markets and state ideologies regarding educational and economic equity shape the experiences of citizens with disabilities.

\section{Conclusions}

Mentioning neoliberal ideology is not customary in discussions of laboratory design or scientific instruments; in fact, ideology of all kinds is elided in the vast majority of STEM education research. In some ways, this essay is an effort simply (!) to see the production of all engineers as a political process. Disabilities Studies seems well placed to enable that kind of view; as Rapley puts it, we can question not merely the content but also the "solidity and inevitability" of knowledge about individuals' competencies" (p. 35). ${ }^{29}$ That approach would seem to encourage precisely the contextualization we want.

Interestingly, the student and instructor in the case described above, with some members of the university's Disabilities Services staff, rapidly escalated their engagement with all of these issues. All have committed themselves to exploring how further change might come about. The school has become a site of meetings and workshops on these issues, convening instructors, students, scientists, and manufacturers of assistive technologies. Each effort has generated more media coverage, a fascinating development in itself (what does it tell us that this is newsworthy activity?). But for the moment we can focus on the ways in which a student enacted a critical intervention. When DS scholars insist that we pay attention to who is defining the problems of persons with disabilities, they help us understand what supports or stands in the way of this subversion of the usual distribution of credibility, authority, and responsibility in STEM education. Also, highlighted, of course, is the constructive nature of critique and resistance.

Does my own study hold constructive potential? There are a number of reasons to think not. From one angle, the non-disabled researcher such as myself can reproduce oppression simply in interrogating the topic. ${ }^{16}$ From another angle, who will listen, anyway? The title of this session, "Look Away Now," is not meant to be facetious but rather to capture an attitude towards difference that assures smooth and familiar social interactions in places of engineering learning and work. If the disabled community member is routinely cast as "wounded," "monstrous" or "abject," in Hughes' striking nomenclature,$^{15}$ then within STEM the disabled body is objectionable in still further ways; it is one that can bring about "substandard" and "imprecise" practice.

But the non-disabled researcher today at least has models for reflexivity that might not have existed in previous scholarly eras. And if Siebers is right and ideologies produce the potential of critique from those who identify as outside that ideology, ${ }^{13}$ this could still be a worthwhile project. Projects aimed at STEM diversity can produce a formal disavowal of bias and include 
legal articulations of fairness, and yet still fail to address structures of opportunity in any deep way. Without episteme-level inquiry, we will never see how STEM exclusion and inclusion are enacted. By looking at the bench-top, in other words, we may see the society in which it operates.

\section{Bibliography}

1. Schaffer, S. (1995.) Accurate measurement is an English science. In M.N. Wise (Ed.), The Values of precision (pp. 135-172). Princeton, NJ: Princeton University Press.

2. Slaton, A. (2001). Reinforced concrete and the modernization of American building, 1900-1930. Baltimore: Johns Hopkins University Press.

3. Gooday, G. J.N. (1995). "The Morals of energy metering: Constructing and deconstructing the precision of the Victorian electrical engineer's ammeter." In M. N. Wise (Ed.), The Values of precision (pp. 239-282). Princeton, NJ: Princeton University Press.

4. Tonso, K.L. (1996). The impact of cultural norms on women. Journal of Engineering Education, 85, 3: 217-225.

5. Cech, E. A. and Waidzunas, T. J. (2011). Navigating the heteronormativity of engineering: the experiences of lesbian, gay, and bisexual students. Engineering Studies, 3: 1, 1-24.

6. Riley, D. and Pawley, A. (2011). Complicating difference: Exploring and exploding three myths about race and gender in engineering education. ASEE Annual Conference.

7. Slaton, A. (2010). Race, rigor and selectivity in U.S. engineering: The history of an occupational color line. Cambridge, MA: Harvard University Press.

8. Riley, D. (2008). Social Justice in engineering. San Rafael: Morgan and Claypool.

9. Slaton, A. (2012). Engineering improvement: Social and historical perspectives on NAE's "Grand Challenges." International Journal of Engineering, Social Justice and Peace 1: 95-108.

10. Pfatteicher, S.K.A. (2005). Anticipating engineering's ethical challenges in 2020. IEE Technology and Society Magazine 24, 4: 4-43.

11. Moon, N.W., Todd, R.L., Morton, D.L., and Ivey. E. (2012). Accommodating students with disabilities in science, technology, engineering and mathematics (STEM). Atlanta, Georgia: Center for Assistive Technology and Environmental Access/SciTrain: Science and Math for All (National Science Foundation).

12. Supalo, C. et al. (2007). Talking tools to assist students who are blind in laboratory courses. Journal of science education for students with disabilities 12, 1: 27-32.

13. Siebers, T. (2010). Disability theory. Ann Arbor: University of Michigan Press.

14. Verstraete, P. (2007). Towards a disabled past: Some preliminary thoughts about the history of disability, governmentality and experience. Educational Philosophy and Theory: 56-63.

15. Hughes, B. (2009.) Wounded/monstrous/abject: A critique of the disabled body in the sociological imaginary. Disability \& Society 24, 4: 399-410. 
16. Humphrey, J.C. (2000). Researching disability politics, or, some problems with the social model in practice. Disability \& Society 15: 1- 36 .

17. National Science Board. (2010.) Preparing the next generation of STEM innovation. Washington, DC: National Science Board/National Science Foundation.

18. Schwartz, R. B., Ferguson, R., and Symonds, B. (2011). Pathways to prosperity: Preparing young Americans for the $21^{\text {st }}$ century. Cambridge, MA: Harvard Graduate School of Education.

19. Popkewitz. T. S. (2004). The Reason of reason: Cosmopolitanism and the governance of schooling. In B. Baker and K. Heyning (Eds.). Dangerous coagulations? The uses of Foucault in the study of education (pp. 189224). New York: Peter Lang.

20. Walkerdine, V. (2003). Reclassifying upward mobility: Femininity and the neo-liberal subject. Gender and Education 15, 3: 237-248.

21. Bourdieu, P. (1998). The State nobility: Elite schools in the field of power. Palo Alto, California: Stanford University Press.

22. Shuttleworth, R., Wedgwood, N., and Wilson, N.J. (2012). The dilemma of disabled masculinity. Men and Masculinities 15: 174-194.

23. Daston, L. and Galison, P. (1992). The image of objectivity. Representations 0, 40: 81-128.

24. Pang, A. S.-J. K. (2002). Empires and the sun. Stanford, CA.: Stanford University Press.

25. Lynch, M. (1985). Art and artifact in laboratory science: A study of shop work and shop talk in a research laboratory. London: Routledge \& Kegan Paul.

26. Saunders, B. F. (2007). CT Suite: The Work of diagnosis in the age of noninvasive cutting. Durham, North Carolina: Duke University Press.

27. Orr, A.C. and Hemmig, S.B. (2009). Inclusive postsecondary strategies for teaching students with learning disabilities: A review of the literature. Learning Disability Quarterly 32, 3: 181-196.

28. Thomas, C. (2004). How is disability understood? An examination of sociological approaches. Disaster \& Society 19, 6: 569-583.

29. Rapley, M. (2004). The Social construction of intellectual disability. West Nyack, NY: Cambridge University Press.

30. Tremain, S. (2005). Foucault and the government of disability. Ann Arbor: University of Michigan Press.

31. Knorr-Cetina, K. (1995). Laboratory studies: The cultural approach to the study of science. In S. Jasanoff, G.E. Markle, J.C. Petersen and T. Pinch (Eds.), Handbook of science and technology studies (pp. 140-166).

Thousand Oaks: Sage Publications.

32. Schaffer, S. (1988). Astronomers mark time: Discipline and the personal equation. Science in Context 2,1: 115145 .

33. Herzig. R. (2006). Suffering for science. New Brunswick: Rutgers University Press.

34. Gould, S.J. (1986). The Mismeasure of man. New York: W.W. Norton.

35. Duster, T. (2003). Backdoor to eugenics ( $2^{\text {nd }}$ edition). New York and London: Routledge, 2003. 
36. Faulkner, W. (2007), "Nuts and bolts and people": Gender troubled engineering identities. Social Studies of Science, 37(3): 331-356.

37. Oldenziel, R. (1999). Making technology masculine. Amsterdam: Amsterdam University Press.

38. Gordon, A. (1995). The Work of corporate culture: diversity management. Social Text, 44: 3-30.

39. Harper, D. (1987.) Working knowledge: Skill and community in a small shop. Chicago: University of Chicago Press.

40. Slaughter, S., \& Rhoades, G. (2004). Academic capitalism and the new economy: Markets, state and higher education. Baltimore: Johns Hopkins University Press.

41. Dunn, C., Rabren, K.S., Taylor, S.L. and Dotson, C.K. (2012). Assisting students with high-incidence disabilities to pursue careers in science, technology, engineering and mathematics. Intervention in School and Clinic 48, 1: 47-54.

42. Slaton, A. (2011). Metrics of marginality: How studies of minority self-efficacy hide structural inequities. ASEE Annual Meeting.

43. Ebeling, M. and Slaton, A. (2013.) Structures of opportunity in the high-tech workforce: A study of American nanolabor. (Manuscript in preparation.)

44. Kleinman, D., \& Vallas, S. (2001). Science, capitalism, and the rise of the "knowledge worker": The Changing structure of knowledge production in the United States." Theory and Society, 30 (4), 451-492. 